\title{
Aplikasi Air Detection Environment System (ADeV) Dalam Mendeteksi Kadar Kualitas Udara Di Area Parkiran Berbasis Android
}

\author{
Ade Silvia Handayani*1, Sopian Soim ${ }^{2}$, Al Fatur Sayid Muhammad ${ }^{3}$, Nyayu Latifah \\ Husni $^{4}$, Rumiasih ${ }^{5}$, Rosmalinda Permatasari ${ }^{6}$ \\ 1,2,3,4,5 Politeknik Negeri Sriwijaya; Jl. Srijaya Negara Bukit Besar 30139 \\ ${ }^{6}$ Universitas Tridinanti; Jl. Kapten Marzuki No.2446 \\ 1,2,3,4,5 Jurusan Teknik Elektro, Politeknik Negeri Sriwijaya Palembang \\ ${ }^{6}$ Jurusan Teknik Sipil, Unversitas Tridinanti Palembang \\ e-mail:*12ade_silvia@polsri.ac.id, ${ }^{2}$ sopian_soim@polsri.ac.id, ${ }^{3}$ afatur470@gmail.com, \\ ${ }^{4}$ nyayu_latifah@polsri.ac.id, ${ }^{5}$ rumiasih@polsri.ac.id, ${ }^{6}$ rosmalinda_mt@yahoo.com
}

\begin{abstract}
Abstrak
Gas buang kendaraan bermotor menjadi salah satu faktor terbesar yang menyebabkan tingginya tingkat polusi udara. Gas buang yang dihasilkan oleh kendaraan mengandung gasgas berbahaya seperti gas $\mathrm{CO}, \mathrm{CO} 2, \mathrm{HC}$ dan lain-lain. Area parkiran indoor merupakan daerah dengan paparan akibat gas buang terbesar selain jalan raya. Untuk mengetahui kadar gas buang di area tersebut, maka perlu dilakukan deteksi terhadap kualitas udara. Terdapat peralatan untuk mendeteksi kadar gas-gas tersebut, namun peralatan tersebut cenderung mahal. Pada Penelitian ini menyajikan Aplikasi Air Detection Environment System berbasis android menggunakan teknologi WSN untuk mendeteksi kadar kualitas udara. Teknologi WSN dengan multi sensor sebagai hardware sistem deteksi kualitas udara di lingkungan parkiran. Aplikasi yang dirancang telah berhasil secara otomatis mendeteksi kualitas udara akibat gas buang kendaraan berupa CO, CO2, HC, PM10, suhu dan kelembaban. Teknologi multi sensor ini dapat mengirimkan data kualitas udara ke server dan ditampilkan aplikasi android berupa tampilan status kualitas udara serta menampilkan waktu dan lokasi kejadian. Adapun kelebihan aplikasi ini ialah masyarakat bisa mengetahui kondisi lingkungan di parkiran secara praktis, real time dan mobile karena cukup membuka aplikasi yang ada di smartphone. Diharapkan dengan adanya aplikasi ini dapat meningkatkan keselamatan dan kewaspadaan pada individu terhadap kualitas lingkungan yang tidak sehat.
\end{abstract}

Kata kunci-android, deteksi, kualitas udara, wireless sensor network.

\begin{abstract}
Vehicle exhaust become one of the biggest factors causing air pollution level. Emmisions produced by vehicles contain dangerous gases, such as $\mathrm{CO}, \mathrm{CO} 2, \mathrm{HC}$, and many more. Indoor parking area is the biggest indoor gas exposures after the main street. To find out the vehicle exhaust levels in those area, it is necessary to do detection of the air quality. There are some tools to detect the air quality, but it also expensive. Through this study, Air Detection Environment System Application that based on android using WSN technology to detect the quality of air. WSN technology along with multi censors as the hardware system are designed to detect the air quality in the indoor parking area. The application can automatically detect the dangerous gases, temperature, also humidity. Multi sensors technology can trasmit the air quality data to the servers and will display it to the android application by the form of air quality states also display time and location of the events. As for the overvalue of this application is people can practically know the environment air quality levels in a real time just
\end{abstract}


with a touch on their smartphone. Hopefully people can increase safety and awareness towards the unhealthy environmental conditions by using this application.

Keywords - android, detection, air quality, wireless sensor network.

\section{PENDAHULUAN}

Polusi udara menjadi salah satu topik permasalahan lingkungan hidup yang selalu diperbincangkan. Hal ini dikarenakan semakin banyak dampak negatif yang disebabkan oleh polusi udara. Berdasarkan data dari Organisasi Kesehatan Dunia (WHO), polusi udara merupakan risiko lingkungan yang besar terhadap kesehatan dan diperkirakan menyebabkan sekitar 6,5 juta orang meninggal tiap tahun [1]. Timbulnya polusi udara disebabkan oleh beberapa hal seperti pembangunan industri dan kontruksi yang terus meningkat. Salah satu faktor terbesar yang menyebabkan meningkatnya polusi udara ialah gas buang hasil dari alat transportasi kendaraan bermotor [2].

Polusi udara terjadi akibat jumlah kendaraan bermotor di perkotaan yang sangat tinggi. Kendaraan bermotor roda dua maupun roda empat menghasilkan gas buang yang sangat berbahaya bagi lingkungan. Kondisi ini menyebabkan lingkungan menjadi tercemar oleh polusi udara, karena gas buang hasil dari oksidasi kendaraan mengandung racun yang berbahaya bagi lingkungan, seperti karbon monoksida (CO) dan hidrokarbon (HC) yang sangat berbahaya bagi kehidupan manusia. Selain itu, proses pembakaran bahan bakar dari motor maupun mobil menghasilkan gas buang yang secara umum mengandung kadar $\mathrm{CO}, \mathrm{CO} 2, \mathrm{NO} 2, \mathrm{HC}, \mathrm{C}, \mathrm{H} 2$, $\mathrm{H} 2 \mathrm{O}$ dan N2 [2].

Kadar gas hasil pembakaran bahan bakar kendaraan dapat diukur menggunakan tools seperti Lutron AQ-9901SD Air Quality Meter [3], National Air Pollution Monitoring Network - NABEL [4] dan lain- lain. Peralatan pengukuran yang digunakan ini memberikan data yang akurat, namun membutuhkan biaya mahal dalam pembangunannya. Pada penelitian [3] [4] telah dikembangkan alat mengukur kualitas udara dengan kemampuan bergerak secara dinamik. Kemampuan sebuah robot pemantau untuk mengukur kadar gas disekitar dengan menggunakan media komunikasi pengiriman data menggunakan bluetooth ke smartphone [5]. Namun, robot pemantau tersebut belum bisa diterapkan secara meluas karena keterbatasan Bluetooth yang memiliki jangkauan pendek sehingga belum bisa diakses diberbagai tempat. Menurut [6][7][8] penggunaan teknologi Wireless Sensor Network lebih effesien sebagai memantau kualitas udara dan mengumpulkan data udara, menilai dan mengevaluasi informasi.

Teknologi Wireless Sensor Network atau WSN pada prinsipnya ialah suatu jaringan tanpa kabel sebagai penghubung antar node. Pemanfaatan teknologi Wireless Sensor Network dengan menggunakan beberapa sensor untuk memonitoring kualitas udara di lokasi yang berbeda-beda [9]. Pada penelitian Tarmidi, menggunakan teknologi WSN dengan node-node sensor yang menyebar pada beberapa lokasi tertentu serta dimonitoring dengan aplikasi android [10]. Penggunaan teknologi WSN dengan sejumlah node sensor khusus dalam mendeteksi dan memantau parameter fisik suatu lingkungan. Beberapa pemantauan yang dilakukan seperti temperatur, kelembaban, tekanan, pergeseran dan lain-lain secara otomatis dengan piranti yang cerdas sehingga mampu mengolah data secara real-time [10] dan data pembacaan akan dikirim ke server dan di tampilkan di smartphone melalui interface aplikasi berbasis android.

Aplikasi berbasis android merupakan sebuah platform perangkat lunak untuk smartphone yang berbasis linux [11]. Sistem operasi android dapat digunakan dan di kembangkan secara terbuka atau open source, hal ini memungkinkan bagi para developer untuk mengatur, memodifikasi atau bahkan membuat aplikasi sendiri. Sistem operasi ini dibuat agar internet bisa

Handayani, et., al [Aplikasi Air Detection Environment System (ADeV) Dalam Mendeteksi Kadar Kualitas Udara di Area Parkiran Berbasis Android] 
digunakan pada smartphone sehingga lebih memudahkan user dan bersifat mobile atau dapat digunakan dimanapun secara flexible tanpa terbatas tempat.

Perancangan sistem pendeteksi kadar kualitas udara telah dilakukan pada beberapa penelitian sebelumnya [12][13]. Pada penelitian Tahir dkk, merancang sistem untuk mengukur kualitas udara berbasis website menggunakan Raspberry pi, modul Wemos D1, MQ135, MQ7, dan DHT11. Penelitian tersebut telah berhasil mengukur kualitas udara dengan parameter suhu, kelembaban, kadar $\mathrm{CO}$ dan $\mathrm{CO} 2$ dan ditampilkan pada interface web di layar laptop [12]. Aplikasi berbasis web akan mendapatkan tampilan user friendly atau mudah dalam mengakses jika dibuka pada browser laptop atau PC, sehingga hal ini akan mengurangi tingkat kepuasan dan loyalitas pengguna dalam mengakses informasi. Sedangkan pada penelitian Pratama dan Setiawan, merancang sistem monitoring kualitas udara berbasis android menggunakan NodeMCU, MQ135 dan DHT 22. Penelitian tersebut telah berhasil memonitoring kualitas udara dengan parameter $\mathrm{CO} 2$, suhu dan kelembaban kemudian data hasil pembacaan sensor ditampilkan pada interface android berupa grafik [13]. Penelitian tersebut telah menggunakan platform android untuk menampilkan data, namun data yang ditampilkan masih minim karena hanya menggunakan dua buah sensor kualitas udara dan menampilkan data pembacaan hanya dalam bentuk grafik.

Berdasarkan survey dari CEM4Mobile Solution, aplikasi berbasis mobile lebih meningkatkan loyalitas dan kepuasan pengguna dalam mengakses informasi karena tampilan yang lebih menarik dan performa yang lebih baik dibandingkan dengan aplikasi berbasis web [14]. Maka dari itu penelitian ini merancang suatu aplikasi mobile berbasis android agar diperoleh tampilan user friendly atau dapat memudahkan user dalam mendapatkan data kondisi kualitas udara, lebih flexible dan cenderung lebih cepat dalam mendapatkan informasi. Selain itu, data yang ditampilkan juga bervariasi untuk meningkatkan pengalaman pengguna maupun kepuasan pelanggan dalam mengakses informasi kualitas udara.

Implementasi teknologi mobile berbasis android pada sistem pendeteksi kualitas udara ini dilakukan karena berdasarkan data yang ditunjukkan oleh lembaga riset digital marketing Emarketer menyatakan bahwa pada tahun 2018 lebih dari 100 juta orang indonesia merupakan pengguna aktif smartphone. Dengan jumlah yang sebesar itu, Indonesia menduduki peringkat keempat terbesar sebagai negara dengan pengguna aktif smartphone setelah Cina, India, dan Amerika [15]. Hal ini mendukung untuk diciptakannya sebuah aplikasi android untuk mengukur kualitas udara agar masyarakat luas dapat mengakses informasi kualitas udara dengan mudah.

Aplikasi android yang digunakan untuk mendeteksi kualitas udara harus memiliki kualitas yang memadai agar dapat digunakan secara luas oleh masyarakat. Menjaga kualitas suatu perangkat aplikasi mobile sangat diperlukan agar tidak terjadi kesalahan pada saat digunakan oleh masyarakat luas. Untuk menghindari banyaknya kesalahan, diperlukan suatu pengujian menggunakan suatu metode sebelum dipublikasikan ke publik agar aplikasi tersebut dapat beroperasi dengan baik [16], salah satu metode yang dapat digunakan ialah metode ISO25010 [16][17][18].

Pada penelitian ini akan merancang sebuah Aplikasi Air Detection Environment System $(\mathrm{ADeV})$ yaitu aplikasi berbasis android yang akan menampilkan data kualitas udara disuatu area parkiran. Perbedaan pada penelitian-penelitian sebelumnya, penelitian ini menampilkan data kualitas udara dalam tiga bentuk tampilan yaitu tampilan real time, history dan grafik. Pada tampilan real time, data kualitas udara yang ditampilkan berupa data terbaru yang terbaca oleh node sensor dan dapat menampilkan lokasi terkini dari node sensor berupa tampilan maps. Pada tampilan history, semua data yang terekam oleh node sensor akan ditampilkan dalam bentuk tabel, sehingga dapat dilihat kondisi kualitas udara pada waktu sebelumnya. Pada tampilan 
grafik, data kadar kualitas udara dapat ditampilkan menggunakan grafik garis pada satuan waktu tertentu. Data kadar kualitas udara yang ditampilkian pada tiga tampilan tersebut didapat dari alat deteksi berupa teknologi WSN dengan multi sensor. Alat deteksi ini akan mendeteksi dan mengirimkan data kualitas udara akibat gas buang kendaraan berupa CO, CO2, HC, PM10, suhu dan kelembaban kemudian ditampilkan pada smartphone berbasis android.

\section{METODE PENELITIAN}

Tahapan dari penelitian ini dimulai pada tahapan rancangan perangkat keras (hardware) dilanjutkan dengan perangkat lunak (software) serta tahapan akhir adalah integrasi sistem serta pengujian sistem. Perancangan perangkat keras sistem pendeteksi kualitas udara menggunakan teknologi WSN berupa alat yang digambarkan melalui blok diagram sistem secara singkat. Hal ini bertujuan untuk mengetahui bentuk umum sistem yang akan dirancang, sehingga dapat memudahkan pada saat proses perancangan perangkat keras.

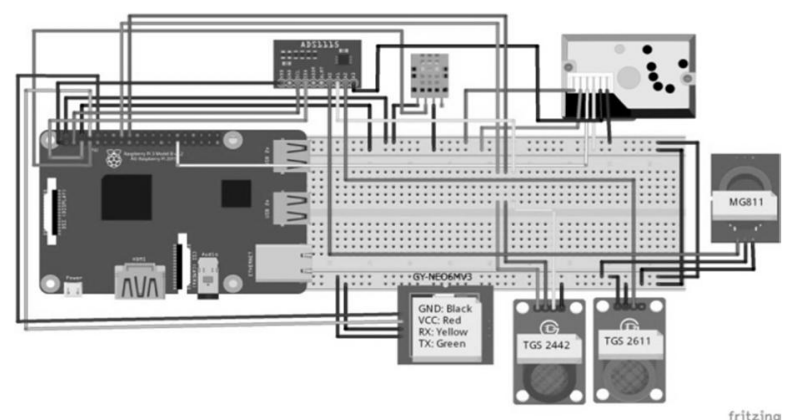

Gambar 1. Diagram Schematic Perangkat Keras

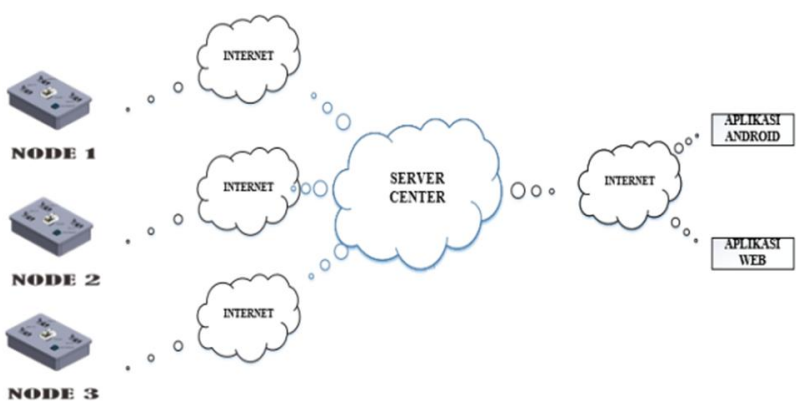

Gambar 2. Diagram Schematic Node Sensor

Pada Gambar 2, merupakan rancangan sistem pendeteksi kualitas udara menggunakan tiga buah node sensor. Masing-masing node sensor terdiri atas beberapa tools pendukung seperti pada Gambar 1. Piranti atau perangkat-perangkat yang digunakan ialah mikroprosessor Raspberry PI 3 model B dilengkapi dengan sensor TGS2442 sebagai sensor pengukur CO, sensor MG811 sebagai sensor pengukur CO2, sensor TGS2611 sebagai sensor pengukur kadar Hidro Karbon, sensor GP2Y1010AU0F sebagai sensor pengukur partikulat debu, sensor GPS Neo6m sebagai sensor untuk memetakan maps dan sensor DHT11 sebagai sensor suhu dan kelembapan. Selain itu, digunakan juga modul ADC atau Analog to Digital Converter yakni ADS1115 sebagai konverter nilai pembacaan sensor agar dapat di proses oleh Raspberry PI sekaligus sebagai modul komunikasi I2C. 
Setelah node-node sensor mengirimkan pembacaan deteksi kualitas udara di lingkungan ke server pusat, maka data hasil pembacaan tersebut akan di olah dan ditampilkan di aplikasi android. Tujuannya agar dapat diakses secara cepat dan mudah untuk mendapatkan informasi keadaan lingkungan tertentu tanpa terbatas tempat maupun waktu.

Pada Gambar 3, merupakan blok diagram dari sistem perangkat lunak (software) yang akan di rancang. Aplikasi android yang dirancang menggunakan software IDE Android Studio. IDE Android Studio adalah software yang digunakan untuk pengembangan aplikasi android yang sudah terintegrasi dengan bahasa XML, java, maupun kotlin. Dalam perancangan aplikasi android ini menggunakan bahasa XML dan java.

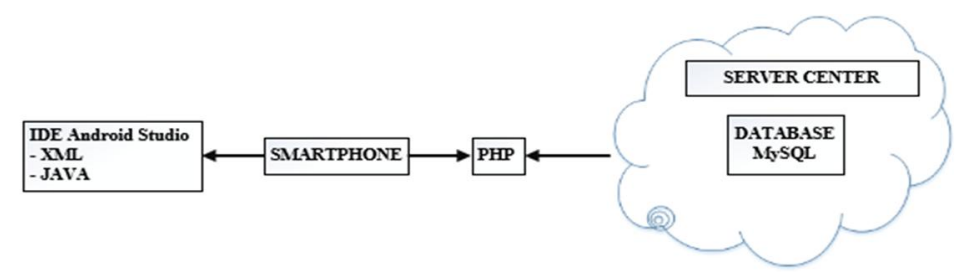

Gambar 3. Blok Diagram Sistem Perangkat Lunak (Software)

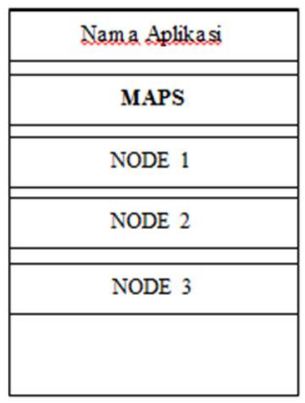

(a)

\begin{tabular}{|c||c|c|}
\hline Nama Aplikas & \multicolumn{2}{|c|}{ REALTME DATA } \\
\cline { 2 - 3 } & \multicolumn{2}{|c|}{ MAPS } \\
\hline NODE $1 / 2 / 3$ & Kuhu & Kelembapan \\
\hline & $C O$ & \multirow{2}{*}{ Air Quality } \\
\hline REAL TIME DATA & CO2 & \\
\hline & HC & Latitude \\
\hline HISTORY & Debs & Longirude \\
\hline GRAFIK & \\
\hline
\end{tabular}

(b)

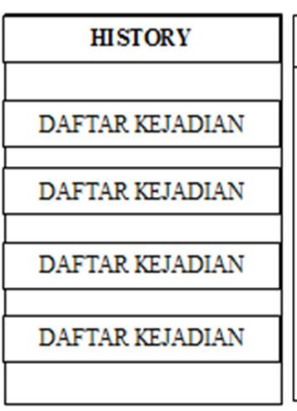

(d)

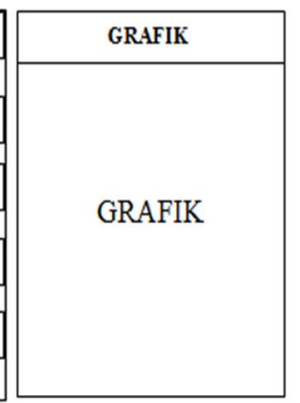

(e)

Gambar 4. Desain Tampilan Aplikasi (a) Dashboard (b) Menu per node (c)Real Time (d) History (e) grafik

Gambar 4 merupakan rancangan desain aplikasi yang akan dibuat sebagai acuan pembangunan aplikasi. Pada tampilan di aplikasi android, halaman dashboard ditunjukkan pada gambar 4(a). Pada gambar tersebut terdapat 3 buah button node dan satu buah maps untuk memetakan node sensor. Saat button node di klik, maka akan tampil menu node seperti pada gambar 4(b). Pada halaman menu node, ada 3 buah pilihan yaitu real time data, history dan grafik. Halaman realtime data ditunjukkan pada gambar 4(c), halaman ini menunjukkan kondisi terkini dari hasil deteksi kadar kualitas udara. Halaman history ditunjukkan pada gambar 5(d), halaman ini menunjukkan data kadar kualitas udara yang direkam oleh node sensor. Sedangkan halaman grafik ditunjukkan pada gambar 4(e). halaman ini akan menampilkan data pembacaan kadar kualitas udara dalam bentuk grafik garis.

Metode pengujian perangkat lunak merujuk pada standar ISO 25010 meliputi metode pengujian functional suitability, Compatibility (Co- existence), performance efficiency dan portability. Metode pengujian yang digunakan menggunakan rumus perhitungan seperti berikut ini.

$$
\text { Presentase Kelayakan }(\%)=\frac{\text { skor yang didapatkan }}{\text { skor maksimum }} \times 100 \%
$$


Setelah angka pengujian diperoleh, kemudian dikalkulasikan nilai persentase kelayakan merujuk pada rumus diatas. Lalu, persentase yang diperoleh diubah ke dalam pernyataan berdasarkan tabel 1 berikut ini.

Tabel 1. Data Persentasi Uji Kelayakan
\begin{tabular}{|c|l|l|}
\hline No & Persentasi (\%) & \multicolumn{1}{|c|}{ Pernyataan } \\
\hline 1 & $0 \%-20 \%$ & Sangat Tidak Layak \\
\hline 2 & $21 \%-40 \%$ & Kurang Layak \\
\hline 3 & $41 \%-60 \%$ & Cukup Layak \\
\hline 4 & $61 \%-80 \%$ & Layak \\
\hline 5 & $81 \%-100 \%$ & Sangat Layak \\
\hline
\end{tabular}

\section{HASIL DAN PEMBAHASAN}

\subsection{Perancangan Perangkat Keras Sistem Pendeteksi Kualitas Udara}

Perancangan perangkat keras (hardware) diterapkan pada sebuah kotak putih. Perangkat keras sistem telah berhasil dibuat berdasarkan sketsa rancangan alat. Pada Gambar 5 (a) menunjukkan tampilan pada perangkat keras sistem pendeteksi kualitas udara dengan Raspberry pi 3 sebagai tempat pemrosesan data yang di baca oleh sensor. Sensor-sensor diletakkan di bagian penutup box dengan tujuan agar dapat membaca kadar kualitas udara disekitarnya.

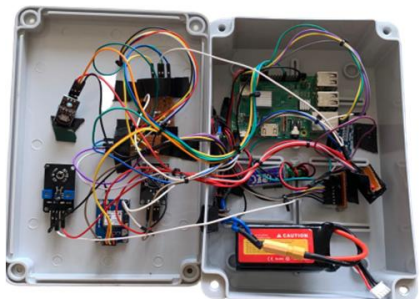

(a)

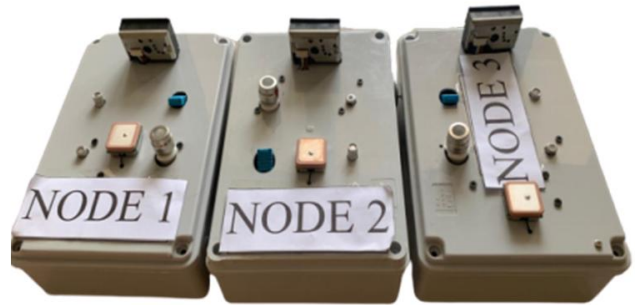

(b)

Gambar 5. Perangkat Keras (hardware) (a) Komponen Dalam (b) Tampak Depan

Pada gambar 5(b) diatas, terdapat tiga buah node sensor yang digunakan, yakni node 1 , node 2 dan node 3. Sensor-sensor yang digunakan diletakkan diatas penutup masing-masing node sensor agar dapat mendeteksi kadar kualitas udara di sekitarnya serta memberikan koordinat peta maps. Adapun sensor-sensor yang digunakan ialah sensor DHT11 berfungsi sebagai sensor pengukur suhu dan kelembapan, sensor MG811 berfungsi sebagai sensor pengukur kadar gas CO2, sensor GP2Y1010AU0F digunakan sebagai sensor pengukur kadar PM10 atau debu, sensor TGS2442 berfungsi untuk mengukur kadar CO, sensor TGS2611 berfungsi untuk mengukur kadar HC, dan modul GPS NEO6M digunakan untuk mendapatkan titik koordinat maps.

\subsection{Perancangan Perangkat Lunak (Software) Sistem Pendeteksi Kualitas Udara}

Perangkat lunak sistem telah berhasil dibuat berdasarkan blok diagram dan desain sketsa tampilan yang telah dibuat. Perangkat lunak yang diperoleh berupa sebuah aplikasi untuk mendeteksi kualitas udara pada lingkungan parkir yang telah terintegrasi dengan smartphone yang dibuat menggunakan software IDE Android Studio. Aplikasi android untuk mengukur kadar kualitas udara ini diberi nama "Air Detection Environment (ADeV) Application". 


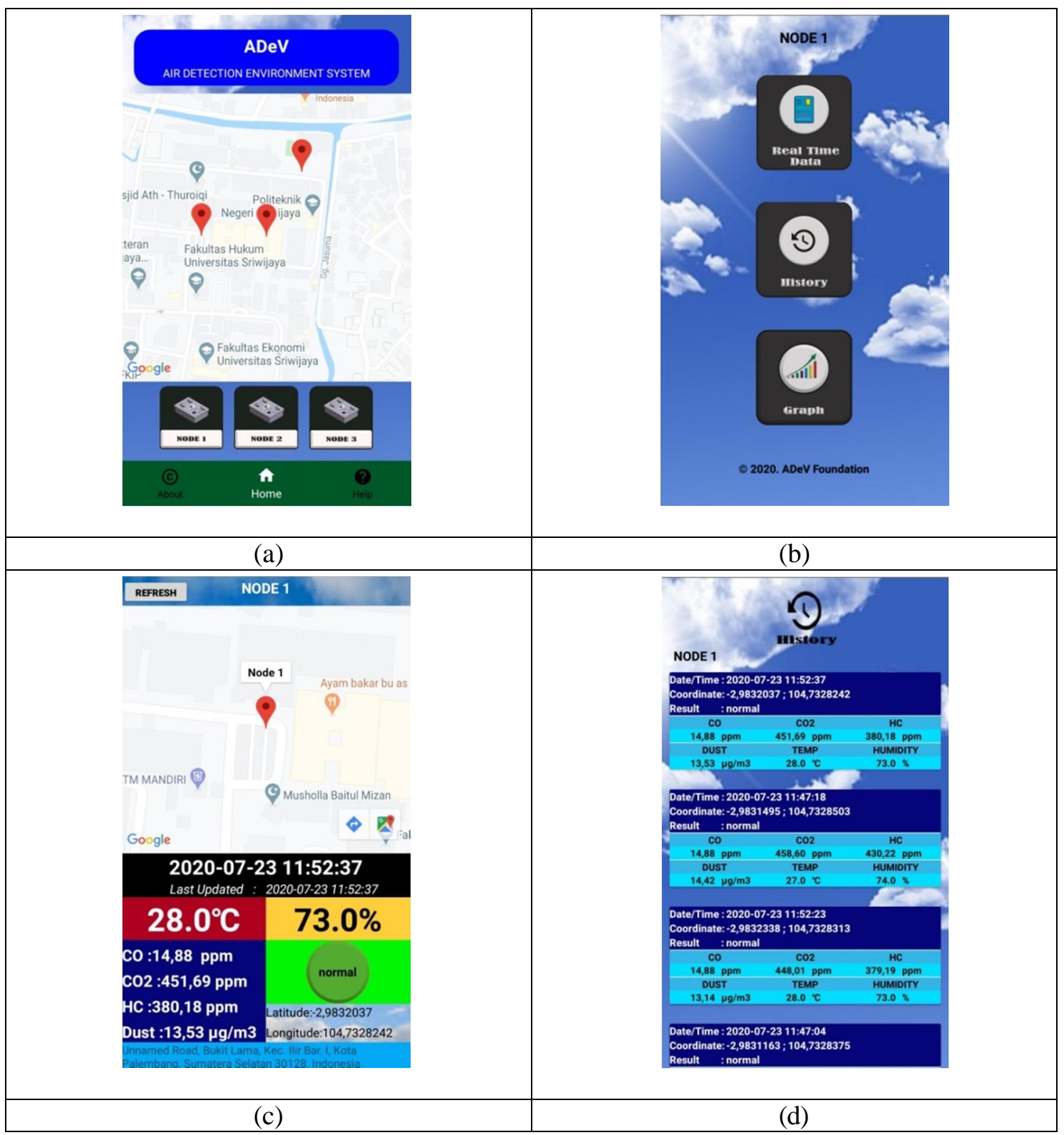

Gambar 6. Layout Tampilan (a) Menu Utama. (b) Menu Node (c) Real Time Data (d) History

Pada gambar 6(a) menunjukkan menu utama pada tampilan aplikasi ADeV. Terdiri atas button node 1 , node 2 , dan node 3 . Selain itu, menu utama juga menampilkan maps untuk lokasi terkini 3 buah node sensor yang digunakan. Pada gambar 6(b) diatas merupakan tampilan jika button node 1 atau node 2 atau node 3 di klik (dalam hal ini diambil sampel node 1). Dalam tampilan tersebut, terdapat 3 menu yang dihasilkan yaitu button real-time data, history, dan grafik.

Pada saat button Real Time Data di klik, maka akan menampilkan layout seperti pada gambar 6(c) diatas. Layout tersebut disebut Real Time Data karena menu ini hanya menampilkan setiap data terbaru dari kadar kualitas udara yang dibaca sensor-sensor secara real 
time. Data akan terus berubah selama masing-masing perangkat node sensor terus membaca data dalam selang waktu tertentu dan tetap terkoneksi ke jaringan internet.

Pada saat button history di klik, maka akan tampil layout seperti pada gambar 6(d) diatas. Tampilan history akan menampilkan semua data kadar kualitas udara maupun titik koordinat maps yang terbaca oleh node sensor.

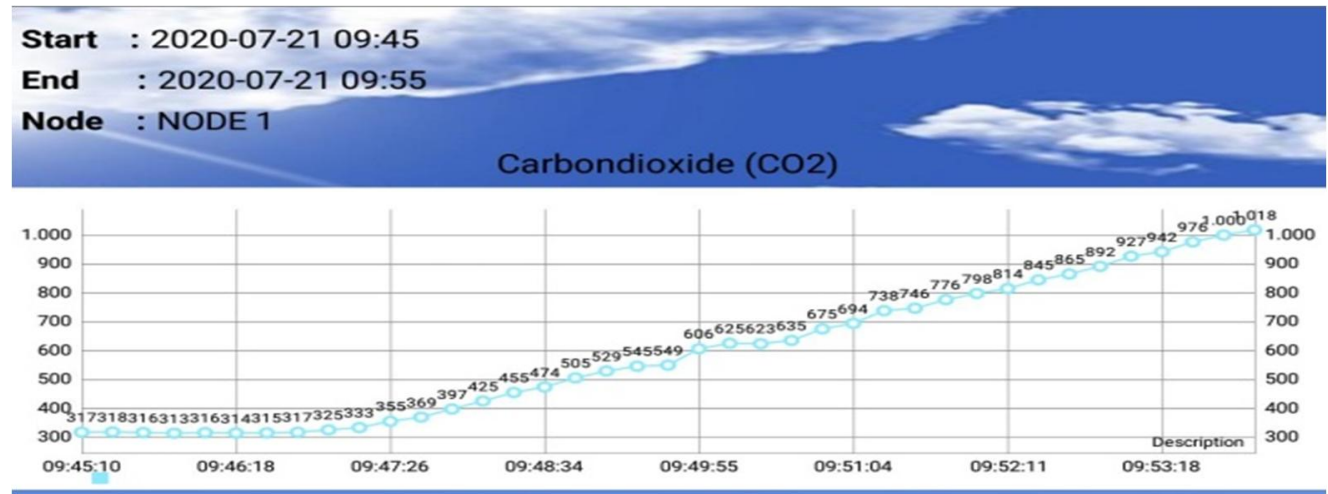

Gambar 7. Layout Tampilan Grafik Garis

Pada gambar 7, grafik akan menampilkan data kadar kualitas udara sesuai node, range waktu yang dipilih dan parameter apa yang ingin di tampilkan. Setelah itu, pada saat button generate di klik, maka akan tampil grafik garis sesuai range waktu dan parameter yang dipilih. Hal ini akan memudahkan masyarakat untuk melihat perkembangan kadar kualitas udara pada waktu tertentu.

\subsection{Pengujian Aplikasi ADeV Menggunakan Standar ISO 25010}

Proses pengujian terakhir dari perancangan ialah pengujian aplikasi. Pengujian menggunakan standar ISO 25010.

\section{1) Pengujian Functional Suitability}

Pengujian Functional Suitability bertujuan untuk memeriksa apakah semua fitur aplikasi yang dirancang dapat dioperasikan atau tidak. Tabel 2 merupakan data pengujian functional suitability.

Tabel 2. Data Pengujian Functional Suitability

\begin{tabular}{|c|c|c|c|c|c|c|c|}
\hline \multirow[b]{2}{*}{ No } & \multirow{2}{*}{ Fitur } & \multicolumn{5}{|c|}{ Penilai } & \multirow{2}{*}{ Nilai } \\
\hline & & 1 & 2 & 3 & 4 & 5 & \\
\hline 1 & Menampilkan Layout Utama & 1 & 1 & 1 & 1 & 1 & 5 \\
\hline 2 & Menampilkan Layout Real Time Data & 1 & 1 & 1 & 1 & 1 & 5 \\
\hline 3 & Menampilkan Layout History & 1 & 1 & 1 & 1 & 1 & 5 \\
\hline 4 & Menampilkan Layout Grafik & 1 & 1 & 1 & 1 & 1 & 5 \\
\hline 5 & Fungsi Tombol & 1 & 1 & 1 & 1 & 1 & 5 \\
\hline 6 & Fungsi Bar & 1 & 1 & 1 & 1 & 1 & 5 \\
\hline & Total & 6 & 6 & 6 & 6 & 6 & 30 \\
\hline
\end{tabular}

$$
\begin{aligned}
\text { Presentase Kelayakan }(\%) & =\frac{\text { skor } \text { yang didapatkan }}{\text { skor maksimum }} \times 100 \% \\
& =\frac{30}{30} \times 100 \% \\
& =100 \%
\end{aligned}
$$


Data perhitungan persentasi yang didapat adalah $100 \%$, maka ditarik kesimpulan semua fitur ADeV 100\% dapat digunakan dengan baik. Berdasarkan presentase tersebut, diperoleh pernyataan "Sangat Layak" pada parameter functional suitability.

\section{2) Pengujian Uji Compatibility}

Aspek compatibility terdiri dari co-existence, pengujian aplikasi yang dijalankan bersama-sama, pengujian di berbagai operating system, dan pengujian tipe perangkat yang berbeda-beda.

Tabel 3. Data Pengujian Co-Existence

\begin{tabular}{|c|c|c|c|c|}
\hline No & \multicolumn{2}{|c|}{ Aplikasi yang dioperasikan } & Berhasil & Gagal \\
\hline 1 & $\mathrm{ADeV}$ & Facebook & 1 & 0 \\
\hline 2 & $\mathrm{ADeV}$ & Google Chrome & 1 & 0 \\
\hline 3 & $\mathrm{ADeV}$ & Instagram & 1 & 0 \\
\hline 4 & $\mathrm{ADeV}$ & Maps & 1 & 0 \\
\hline 5 & $\mathrm{ADeV}$ & Youtube & 1 & 0 \\
\hline 6 & $\mathrm{ADeV}$ & Gojek & 1 & 0 \\
\hline \multicolumn{3}{|c|}{ Total } & 6 & 0 \\
\hline
\end{tabular}

Tabel 3 hasil pengujian co-existence di atas merepresentasikan data pengujian aplikasi $\mathrm{ADeV}$ yang dijalankan bersamaan dengan 6 aplikasi yang berbeda pada satu smartphone yang sama. Berdasarkan pengujian, diperoleh data persentasi sebagai berikut:

$$
\begin{aligned}
\text { Presentase Kelayakan }(\%) & =\frac{\text { skor yang didapatkan }}{\text { skor maksimum }} \times 100 \% \\
& =\frac{30}{30} \times 100 \% \\
& =100 \%
\end{aligned}
$$

Hasil persentase yang diperoleh adalah $100 \%$, maka diambil kesimpulan bahwa aplikasi $\mathrm{ADeV}$ dari sisi Co-Existence "Sangat Layak".

Tabel 4 merupakan data uji $\mathrm{ADeV}$ yang dijalankan pada operating system dan smartphone yang berbeda-beda. Pengujian meliputi setup suite atau instalasi, build-in explorer atau proses menjalankan, dan teardown suite atau menghapus aplikasi.

Tabel 4. Ringkasan Pengujian pada Operating System dan Tipe Perangkat.

\begin{tabular}{|c|l|c|c|c|c|}
\hline No & \multicolumn{1}{|c|}{ Perangkat } & $\begin{array}{c}\text { Setup } \\
\text { Suite }\end{array}$ & $\begin{array}{c}\text { Build-in- } \\
\text { Explorer Suite }\end{array}$ & $\begin{array}{c}\text { Teardown } \\
\text { Suite }\end{array}$ & Skor \\
\hline 1 & Xiaomi Redmi 4A (7.1.2) & 1 & 1 & 1 & 3 \\
\hline 2 & Samsung J2 Pro (7.1.1) & 1 & 1 & 1 & 3 \\
\hline 3 & Asus (9.0) & 1 & 1 & 1 & 3 \\
\hline 4 & Xiaomi redmi 3S (6.0.1) & 1 & 1 & 1 & 3 \\
\hline 5 & Oppo A37(5.1.1) & 0 & 0 & 0 & 0 \\
\hline 6 & Samsung galaxy J3 pro (7.0) & 1 & 1 & 1 & 3 \\
\hline 7 & Samsung J5 Prime (8.0) & 1 & 1 & 1 & 3 \\
\hline \multicolumn{2}{|c|}{ Total } & 6 & 6 & 6 & 21 \\
\hline
\end{tabular}

Pada data ringkasan tersebut, diperoleh persentase kelayakan berikut.

$$
\text { Presentase Kelayakan }(\%)=\frac{\text { skor yang didapatkan }}{\text { skor yang maksimum }} \times 100 \%
$$




$$
\begin{aligned}
& =\frac{30}{30} \times 100 \% \\
& =100 \%
\end{aligned}
$$

Data perhitungan yang diperoleh adalah $85 \%$, maka $\mathrm{ADeV}$ memenuhi uji compatibility dengan predikat "Sangat Layak".

\section{3) Pengujian Portability}

Pengujian portability dilaksanakan dengan mengoperasikan $\mathrm{ADeV}$ pada perangkat mobile Android yang memiliki sistem operasi dan ukuran layar yang berbeda. Berdasarkan Tabel 5 dapat diketahui bahwa hasil pengujian portability aplikasi $\mathrm{ADeV}$ menunjukkan ada yang "Berhasil" dan ada yang "Gagal". Dalam hal ini yang dominan adalah kriteria "Berhasil" diartikan bahwa setiap fungsi yang terdapat pada aplikasi dapat berjalan dengan baik ketika aplikasi dijalankan pada beberapa sistem operasi dan resolusi layar yang bervariasi.

Tabel 5. Data Uji Portability

\begin{tabular}{|c|l|c|}
\hline No & \multicolumn{1}{|c|}{ Aspek yang Dinilai } & Hasil Pengujian \\
\hline A & \multicolumn{1}{|c|}{ Sistem Operasi } & \\
\hline 1 & Lollipop & Gagal \\
\hline 2 & Marshmallow & Berhasil \\
\hline 3 & Nougat & Berhasil \\
\hline 4 & Oreo & Berhasil \\
\hline 5 & Pie Rerhasil \\
\hline B & Resolusi Layar & \\
\hline 1 & MDPI : WXGA (1280 x 800 piksel) & Berhasil \\
\hline 2 & HDPI : WVGA (480 x 800 piksel) & Berhasil \\
\hline 3 & LDPI : WSVGA (1024x600 piksel) & Berhasil \\
\hline
\end{tabular}

\section{4) Pengujian Performance Efficiency}

Pengujian performance efficiency dilaksanakan dengan cara menghitung rata-rata waktu respon aplikasi $\mathrm{ADeV}$ untuk launching. Pada pengujian ini, dilakukan sebanyak 3 kali dengan tiga macam smartphone berbeda dan spesifikasi yang berbeda.

Pada tes 1 smartphone Android yang digunakan memiliki spesifikasi: RAM 2 GB; CPU quad-core 1.4GHz Cortex-A53; dan OS Android 7.1.1 (Nougat). Pada tes 2 smartphone Android yang digunakan memiliki spesifikasi: RAM 1.5 GB; CPU Qualcomm Snapdragon 425; dan OS Android 6.0.1 (Marshmallow). Pada tes 3 smartphone Android yang digunakan memiliki spesifikasi: RAM 6 GB; CPU Snapdragon 636; OS Android 9.0 (Pie).

Tabel 6. Hasil Uji Performance Efficiency

\begin{tabular}{|c|l|c|c|c|}
\hline \multirow{2}{*}{ No } & \multirow{2}{*}{ Kategori } & \multicolumn{3}{c|}{ Response Time $(\mathbf{s})$} \\
\cline { 3 - 5 } & & Tes 1 & Tes 2 & Tes 3 \\
\hline 1 & Splash Screen (launch time) & 4.85 & 4.99 & 4.26 \\
\hline 2 & Menampilkan menu Utama & 2.39 & 2.35 & 2.20 \\
\hline 3 & Menampilkan menu Node & 0.8 & 1.11 & 0.50 \\
\hline 4 & Menampilkan Layout Real-Time Data & 1.69 & 1.82 & 1.56 \\
\hline 5 & Menampilkan Layout History & 3.88 & 4.76 & 1.19 \\
\hline 6 & Menampilkan Layout Grafik & 4.73 & 5.22 & 3.53 \\
\hline \multicolumn{2}{|c|}{ Jumlah } & 18,34 & 20,27 & 13,24 \\
\hline Rata-rata & 3,06 & 3,39 & 2,21 \\
\hline
\end{tabular}


Dari pengujian disimpulkan bahwa jenis prosesor dan RAM memengaruhi nilai performa suatu aplikasi. Pengujian pada tes ke 3 diperoleh hasil yang lebih cepat jika dibandingkan dengan tes 1 dan tes 2 . Hal ini dikarenakan untuk tes 3 menggunakan prosesor dan RAM tertinggi.

\subsection{Pengujian Aplikasi ADeV Dalam Mendeteksi Kadar Kulitas Udara}

Hasil pengujian ini dilakukan untuk menguji hasil perancangan aplikasi ADeV dalam mendeteksi kualitas udara. Pengujian dilakukan dengan mengintegrasikan aplikasi ADeV dengan hanya satu buah node sensor untuk mendapatkan hasil deteksi kadar kualitas udara.

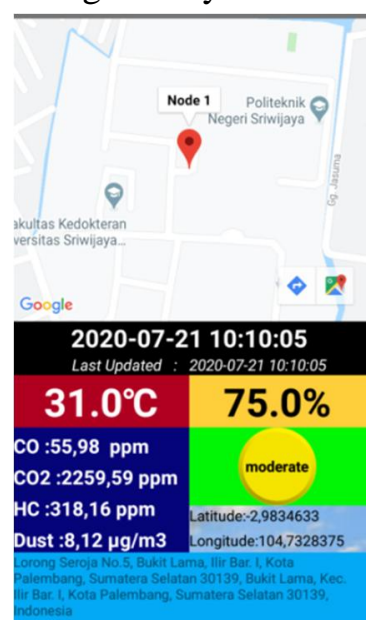

(a)
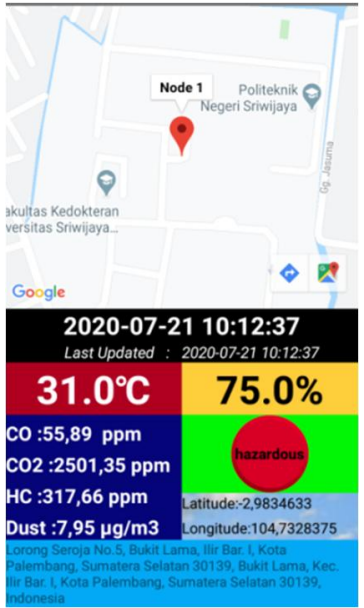

(b)

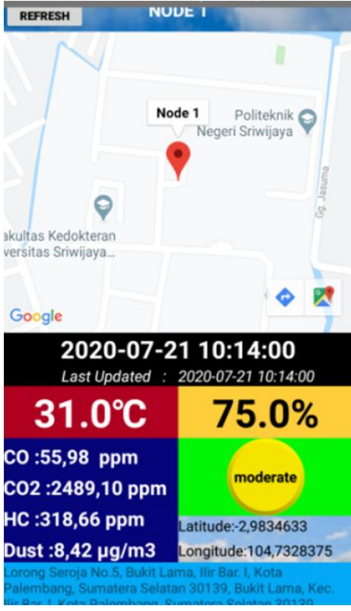

(c)

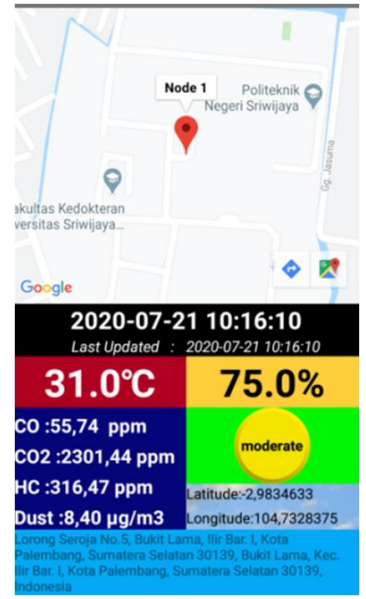

(d)

Gambar 8. Tampilan Real Time pada Tanggal 21-07-2020 Pukul 10.10 - 10.16

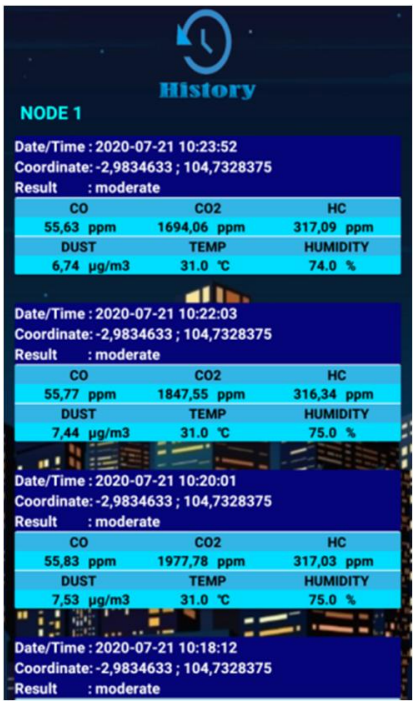

(a)

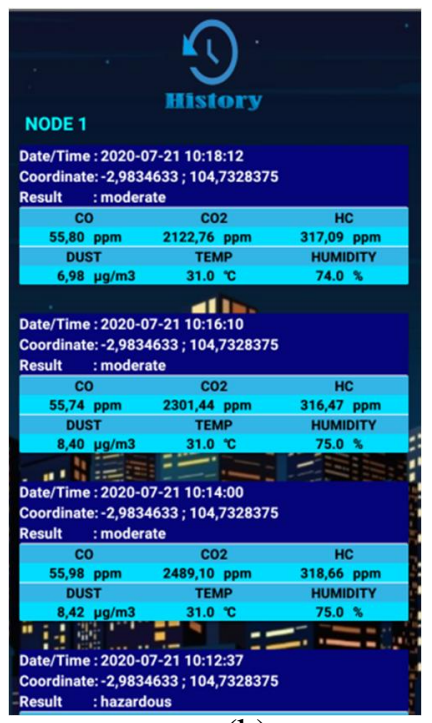

(b)

Gambar 9. Tampilan History Tanggal 21-07-2020 (a) Pukul 10.23-10.20 (b) Pukul 10.18-10.14 
Start : 2020-07-21-09:45

End : 2020-07-21 10:25

Node : NODE 1

Carbonmonoxide (CO)

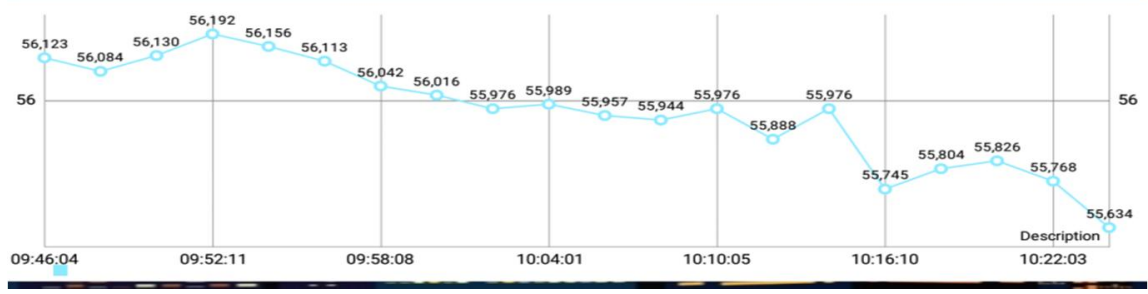

Gambar 10. Grafik Kadar CO
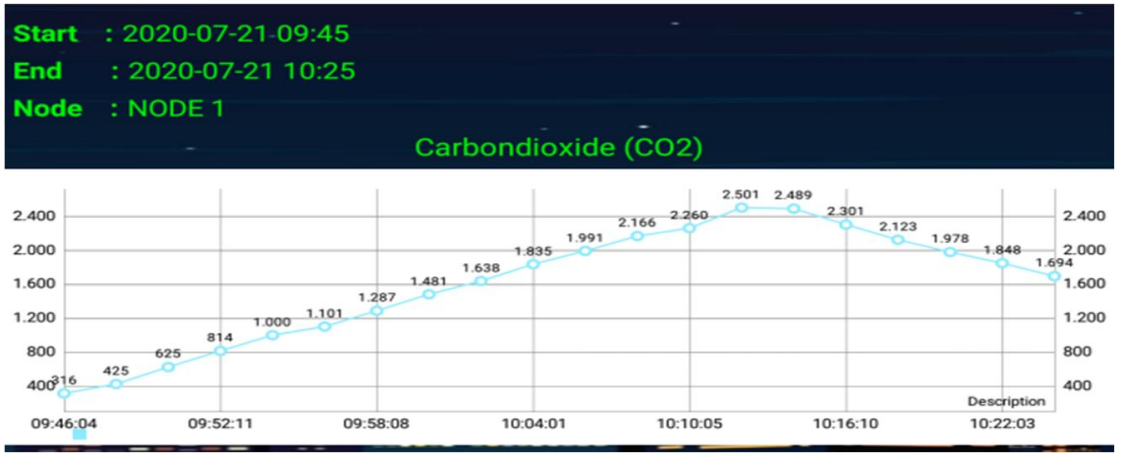

Gambar 11. Grafik Kadar CO2

Start : 2020-07-21-09:45

End : 2020-07-21 10:25

Node : NODE 1

\section{Hydro Carbon (HC)}

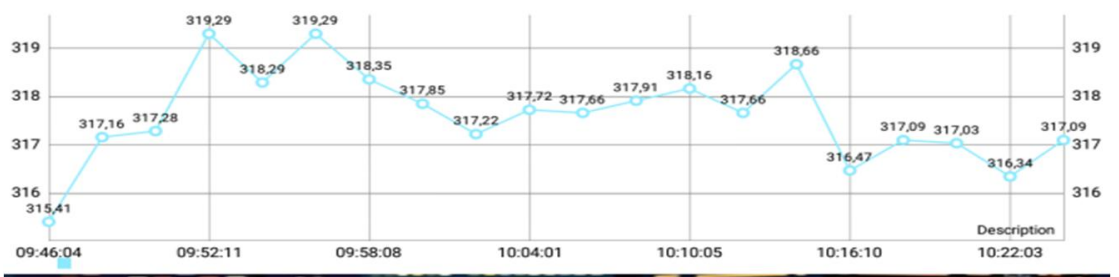

Gambar 12. Grafik Kadar HC

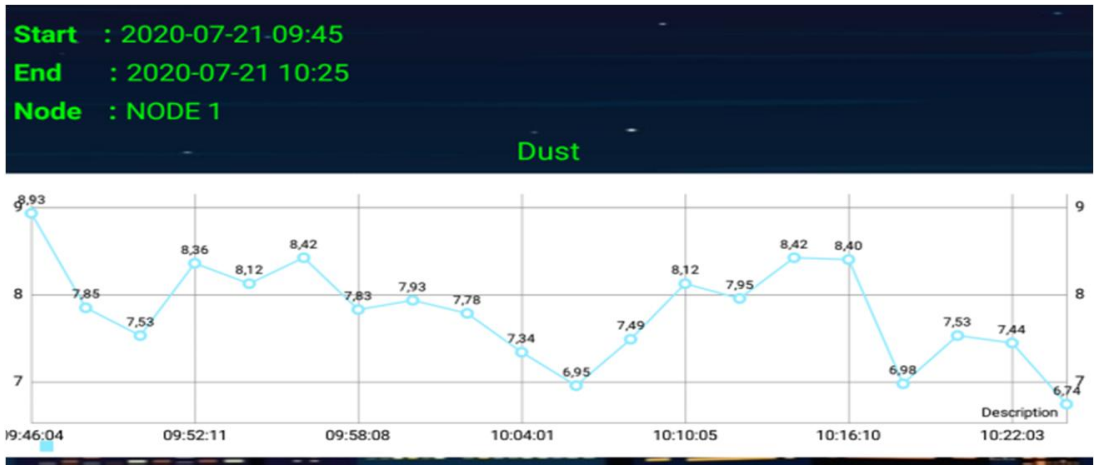

Gambar 13. Grafik Kadar Debu 


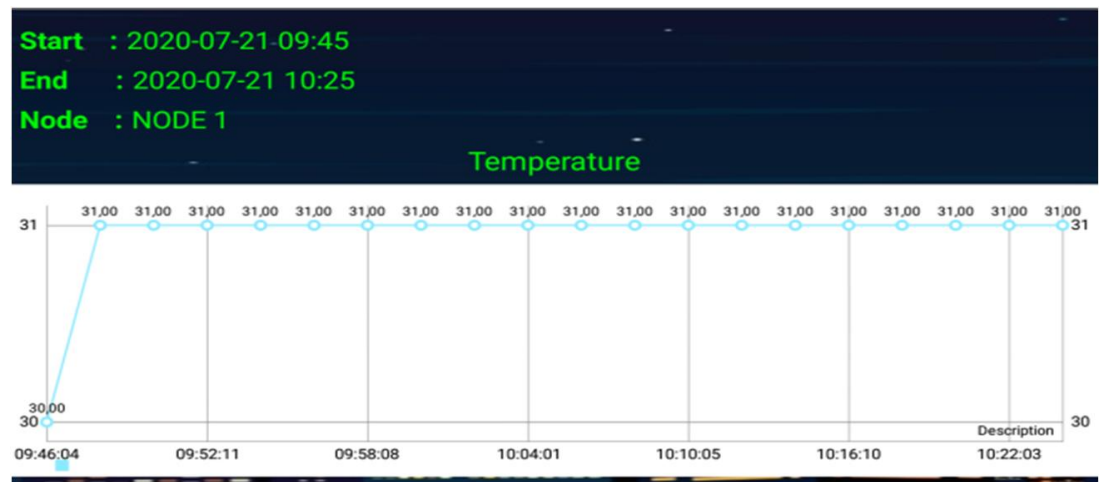

Gambar 14. Grafik Suhu

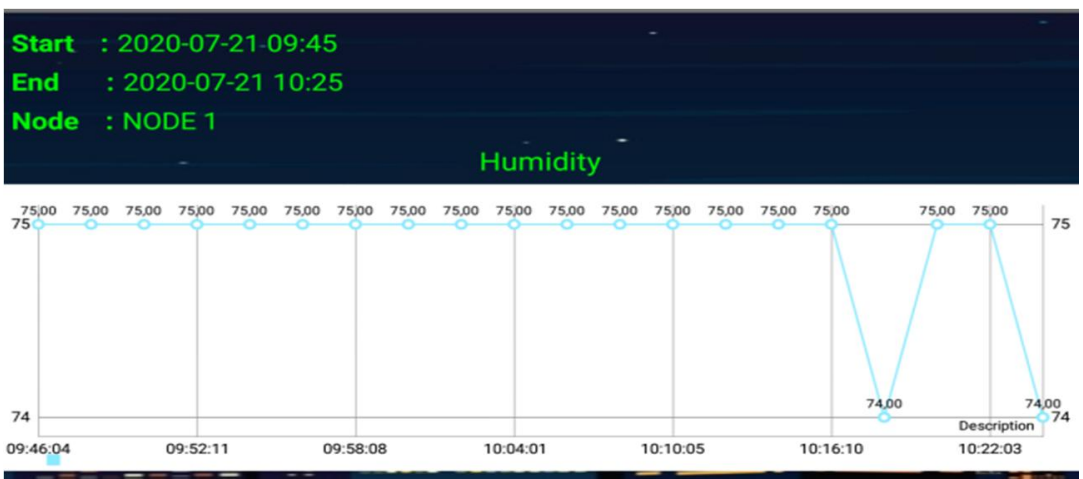

Gambar 15. Grafik Kelembaban

Berdasarkan data Real Time pada gambar 8, aplikasi ADeV memiliki kinerja yang baik karena dapat mengirimkan informasi tanpa selang waktu atau real time. Pada gambar tersebut terdapat lingkaran kuning dan merah. Lingkaran kuning menunjukkan bahwa kualitas udara pada saat itu ialah Moderate, sedangkan lingkaran merah menunjukkan bahwa kualitas udara saat itu ialah Hazardous. Lokasi berupa latitude dan longitude tampil sesuai dengan lokasi perangkat yang terdisplay pada maps.

Pada Gambar 9, menampilkan history pembacaan sensor, perekaman waktu terjadi serta lokasi node sensor. Tampilan ini memiliki kinerja yang baik karena dapat menampilkan data history yang ada di database webserver. Pada Gambar 10-15 merupakan hasil pembacaan sensor dalam bentuk grafik pada satuan waktu tertentu. Grafik ini juga memiliki kinerja yang baik karena dapat menampilkan nilai pembacaan sensor yang ada di database dalam bentuk diagram garis.

\subsection{Analisa Kinerja Aplikasi ADeV}

Dari percobaan yang telah dilakukan mulai dari perancangan perangkat keras (hardware), tahap kedua perancangan perangkat lunak (software), dan tahap ketiga yaitu integrasi perangkat hardware dan software.

Perancangan perangkat keras (hardware) diawali dengan pemilihan komponen berdasarkan fungsi dan kegunaan. Pada perancangan hardware node sensor ini penulis menggunakan mikroprosessor Raspberry PI 3 untuk memberikan perintah, memproses seluruh masukan dan mengatur seluruh keluaran, sensor-sensor kualitas udara sebagai input dan sensor GPS dan I2C sebagai modul pendukung. Sensor TGS2442 digunakan sebagai sensor CO, sensor 2611 digunakan sebagai sensor $\mathrm{HC}$, sensor MG811 sebagai sensor CO2, sensor 
GP2Y1010AU0F sebagai sensor partikulat debu, dan sensor DHT11 sebagai sensor suhu dan kelembapan.

Untuk perancangan perangkat lunak (software) dibuat menggunakan program Android Studio. Aplikasi ADeV yang di rancang menyediakan beberapa fitur yakni menyediakan informasi kualitas udara. Informasi kualitas udara yang dapat diakses meliputi kondisi real time, history maupun grafik kadar gas pada saat tertentu. Real Time digunakan untuk melihat kondisi kualitas udara yang terbaru, fitur history dan grafik agar data sebelumnya dapat dilihat dan diakses.

Kualitas aplikasi $\mathrm{ADeV}$ mendapatkan hasil pengujian functional suitability "sangat layak" karena semua fitur $\mathrm{ADeV}$ beroperasi dengan lancar. Pada pengujian compatibility "sangat layak" karena ADeV dapat beroperasi bersamaan dengan aplikasi lainnya. Sedangkan untuk aspek portability aplikasi dinyatakan "layak" karena aplikasi dapat berjalan pada berbagai ukuran layar dari sebuah perangkat dan dapat dioperasikan pada beberapa tipe perangkat dan versi android dengan minimal android Marshmallow dan maksimal Pie. Untuk hasil uji performance efficiency, aplikasi $\mathrm{ADeV}$ memiliki respons yang cepat dalam menampilkan layout maupun mengambil data yang tersimpan di database server.

Data yang ditampilkan android ialah hasil integrasi node sensor yang mengirimkan data secara wireless ke server, kemudian data disimpan kedalam database. Lalu android membaca data di server menggunakan protokol HTTP agar bisa mengakses data untuk ditampilkan pada perangkat android milik pengguna. Karena sistem ini berbasis IOT, maka diperlukan koneksi internet yang memadai agar didapat data yang akurat dan real time.

\section{KESIMPULAN}

Aplikasi ADeV sebagai aplikasi sistem pendeteksi kualitas udara berbasis android mempunyai kemampuan yang baik untuk mendeteksi kualitas udara berupa tampilan real time data kadar kualitas udara, history, maupun grafik. Pada tampilan real time, aplikasi ADeV berhasil menampilkan data terbaru dari kadar kualitas udara serta dapat menampilkan lokasi terkini dari node sensor yang digunakan. Pada tampilan history, aplikasi ADeV telah berhasil menampilkan semua data pembacaan yang dibaca oleh node sensor. Pada tampilan grafik, aplikasi $\mathrm{ADeV}$ telah berhasil menampilkan pembacaan data dalam bentuk grafik garis pada satuan waktu dan parameter tertentu yang dipilih.

Berdasarkan standard ISO 25010, sistem pendeteksi kualitas udara menggunakan aplikasi $\mathrm{ADeV}$ memiliki persentase uji functional suitability sebesar $100 \%$, artinya semua fitur aplikasi $\mathrm{ADeV}$ dapat dioperasikan dengan lancar. Pada uji compatibility, terdiri atas uji co-existence atau pengujian aplikasi yang dijalankan bersama-sama dengan aplikasi lain, pengujian di berbagai OS dan berbagai tipe perangkat yang berbeda. Uji co-existence memperoleh persentase sebesar $100 \%$ dapat dijalankan bersama-sama dengan aplikasi lain, pengujian di berbagai OS dan tipe perangkat yang berbeda memperoleh persentase $85 \%$, artinya aplikasi $\mathrm{ADeV}$ dapat dijalankan pada semua tipe perangkat yang memiliki sistem operasi minimum 6.0.

Pada uji portability atau mengoperasikan $\mathrm{ADeV}$ pada perangkat Android yang memiliki sistem operasi dan ukuran layar yang berbeda, diperoleh hasil bahwa aplikasi ADeV dapat berjalan pada sistem operasi minimum Marshmallow dan berhasil dijalankan pada resolusi layar HDPI, MDPI maupun LDPI. Pada pengujian performance efficiency, dilaksanakan dengan cara menghitung rata-rata waktu respon aplikasi ADeV untuk launching masing-masing tampilan. Pada pengujian tersebut, diperoleh kesimpulan bahwa jenis prosesor dan RAM memengaruhi performa dalam suatu aplikasi. Secara keseluruhan, sistem pendeteksi kualitas berbasis android dinilai sangat layak dan flexible jika dibandingkan menggunakan komputer atau laptop.

Handayani, et., al [Aplikasi Air Detection Environment System (ADeV) Dalam Mendeteksi Kadar Kualitas Udara di Area Parkiran Berbasis Android] 


\section{SARAN}

Berdasarkan kesimpulan penelitian, maka penulis merekomendasikan saran-saran untuk menutup kekurangan pada penelitian ini yakni pengembangan aplikasi yang lebih baik lagi serta tampilan yang di desain lebih menarik dan lebih banyak memuat informasi agar aplikasi yang digunakan lebih optimal dan bermanfaat untuk pengguna.

\section{UCAPAN TERIMA KASIH}

Penulis menyampaikan penghargaan sebesar-besarnya kepada Kementerian Pendidikan dan Kebudayaan, Kementerian Riset dan Teknologi/Badan Riset dan Inovasi Nasional (Kemenristek/BRIN) Republik Indonesia dan Politeknik Negeri Sriwijaya mendukung dan mendanai penelitian ini. Penulis mengucapkan terima kasih khusus kepada rekan-rekan Prodi Teknik Telekomunikasi, Jurusan Teknik Elektro Polsri. Penulis juga ingin mengucapkan terima kasih kepada teknisi Laboratorium Teknik Telekomunikasi dan Laboratorium Teknik Elektronika atas bantuan dalam sarana dan prasarana dalam menjalankan penelitian ini.

\section{DAFTAR PUSTAKA}

[1] M. Kurniawati, Nurullita, 2017, Indikator Pencemaran Udara Berdasarkan Jumlah Kendaraan dan Kondisi Iklim (Studi di Wilayah Terminal Mangkang dan Terminal Penggaron Semarang ), Jurnal Kesehatan Masyarakat, Vol. 12, No. 2, pp. 19-24.

[2] R. A. Saputra and A. Amajid, 2018, Analisis Kadar Emisi Gas Buang pada Sepeda Motor Berbahan Bakar Gas LPG dan Pertalite Dengan Variasi Tekanan Kompresi, Diploma, Universitas Muhammadiyah Magelang.

[3] T. Klein, A. Vasl, G. Kadas, and L. Blaustein, 2017, Measuring The Effect of PlantCommunity Composition on Carbon Fixation on Green Roofs, Urban Forestry \& Urban Greening, Vol. 24, pp. 1-4.

[4] A. Arfire, A. Marjovi, and A. Martinoli, 2016, Mitigating Slow Dynamics of Low-Cost Chemical Sensors for Mobile Air Quality Monitoring Sensor Networks, in Proceeding EWSN '16 Proceedings of the 2016 International Conference on Embedded Wireless Systems and Networks, pp. 159-167.

[5] E. Prihatini, S. Rasyad, N. L. Husni, A. S. Handayani, E. Evelina, and R. Handayani, 2018, Robot Pemantau Kualitas Udara Berbasis Android, Jurnal TIPS: Jurnal Teknologi Informasi dan Komputer Politeknik Sekayu, Vol. 8, No. 1, pp. 74-80.

[6] S. U. Zagade and R. S. Kawitkar, 2012, Wireless Sensor Network for Greenhouse, Vol. 2, No. 3, pp. 130-133.

[7] S. R. B. Prabhu, M. Pradeep, and E. Gajendran, 2017, Monitoring Climatic Conditions Using Wireless Sensor, A Multidisciplinary Journal of Scientific Research \& Education, Vol. 3, No. 1, pp. 179-184.

Handayani, et., al [Aplikasi Air Detection Environment System (ADeV) Dalam Mendeteksi Kadar Kualitas Udara di Area Parkiran Berbasis Android] 
[8] A. Nasre, R. Barai, and P. Walde, 2014, Design of Greenhouse Control System Based on Wireless Sensor Networks Using MATLAB, Discovery, Vol. 19, No. 57, pp. 56-58, doi: 10.4304/jnw.6.12.1668-1674.

[9] D. I. Pujiana, A. S. Handayani, and A. Aryanti, 2017, Perancangan Wireless Sensor Network Dalam Sistem Monitoring Lingkungan, Prosiding Annual Research Seminar 2017 Computer, Vol. 3, No. 1.

[10] Tarmidi, Ahmad Taqwa, and A. S. Handayani. 2019, Penerapan Wireless Sensor Network Sebagai Monitoring Lingkungan Berbasis Android, Seminar Nasional Inovasi dan Aplikasi Teknologi di Industri 2019, pp. 224-230.

[11] B. C. Neyfa and D. Tamara, 2016, Perancangan Aplikasi E-Canteen Berbasis Android Dengan Menggunakan Metode Object Oriented Analysis \& Design (OOAD), J. Penelit. Komun. dan Opini Publik, Vol. 20, No. 1, pp. 83-92.

[12] F. Tahir, W. Ridwan, and I. Z. Nasibu. 2020, Monitor Kualitas Udara Berbasis Web Menggunakan Raspberry Pi dan Modul Wemos D1, Jurnal Teknik, Vol. 18, No. 1, pp. 35-44.

[13] K. Pratama and E. B. Setiawan. 2017, Implementasi Monitoring Kualitas Udara Menggunakan Peramalan Exponential Smoothing dan NodeMCU Berbasis Mobile Android, Ultima Computing: Jurnal Sistem Komputer, Vol. 9, No. 2, pp. 58-66.

[14] Tekno Jurnal, Data Survey Aplikasi Mobile VS Web Mobile, 2020.

[15] Kominfo, Indonesia Raksasa Teknologi Digital Asia, 2020.

[16] R. Rudi and D. R. Prehanto, 2020, Pengembangan Aplikasi Sistem Pengelolaan Data Prestasi Mahasiswa Berdasarkan Standar ISO/IEC 25010, Jurnal Manajemen Informatika, Vol. 11, No. 1.

[17] S. Rahayuda, 2017, Evaluasi Penggunaan Framework Laravel pada E-Government Menggunakan ISO/IEC 25010: 2011, Jurnal Ilmu Pengetahuan dan Teknologi Komunikasi, Vol. 19, No. 1, pp. 81-94.

[18] A. R. Soedjono, 2016, Pengujian Kerahasiaan Data dan Otentisitas Pengguna pada Sistem E-PKK Online Menggunakan ISO 25010, Institut Teknologi Sepuluh Nopember Surabaya. 